\title{
SOBRE LA EXIGIBILIDAD JUDICIAL DÉBIL DE LOS DERECHOS SOCIALES: ESCUCHAR AL TEDH, O HACERLO DECIR
}

\author{
THE JUDICIABLITY OF SOCIAL RIGHTS: LISTENING TO THE ECTHR \\ OR MAKING IT SAY
}

\begin{abstract}
Julio PoHL ${ }^{*}$
RESUMEN: Algunos autores afirman que el Tribunal Europeo de Derechos Humanos $(\mathrm{TEDH})$ adjudica derechos sociales por vía de conexión indirecta entre derechos civiles y derechos sociales. Esto pone en entredicho la legitimidad de las decisiones de este Tribunal supranacional pues su pacto constitutivo lo limita a conocer exclusivamente en materia de derechos civiles. En aras de analizar el respeto a los márgenes de creatividad en la interpretación judicial, este trabajo clasifica cinco niveles de derechos sociales, identificando tanto el caso central como los de la penumbra, con el fin de revisar la anterior afirmación en la jurisprudencia más reciente y relevante de este tribunal a la luz de esta clasificación.
\end{abstract}

Palabras clave: Derechos sociales, interpretación judicial, caso central y casos de penumbra, TEDH.

ABSTRACT: Some authors assert that the European Court of Human Rights (ECtHR) adjudicates social rights through an indirect connection between civil rights and social rights. This puts into question the legitimacy of its decisions, being that it is a civil rights' exclusive supranational Court. In order to review the degree of respect for the creativity margins in judicial interpretation, this paper classifies five levels of social rights, identifying both the central case and those of the penumbra, in order to review the previous statement in the most recent and relevant caselaw of this Court in light of this classification.

Keywords: Social Rights, judicial interpretation, central case and penumbra, ECtHR.

\section{INTRODUCCIÓN}

La clasificación de los derechos humanos en dos grandes compartimentos es causa de numerosos e intensos debates, por una parte, el de los derechos civiles y políticos (de ahora en adelante derechos civiles) y, por otra, el de los derechos económicos, sociales y culturales (de ahora en adelante derechos sociales) ${ }^{1}$. Entre las consideraciones teóricas y

\footnotetext{
* Máster en Derechos Humanos y Doctorando en Filosofía del Derecho, Universidad de Navarra (España). Dirección postal: Biblioteca de Humanidades, Campus Universitario, 31009 Pamplona, España. Correo electrónico: jpohl@alumni.unav.es. Agradezco especialmente a la Dra. Pilar Zambrano por su amable orientación y oportunos consejos para la elaboración de este trabajo.
}

1 Confróntese con Ulloa y Mayo (2015); Figueroa García-Huidobro (2009-a) y (2009-b). Sobre la naturaleza de ambos derechos véase Del CARRIL (2012). 
prácticas surgidas en torno a la igual -o desigual- naturaleza de los derechos humanos se encuentra la cuestión sobre la exigibilidad judicial ${ }^{2}$.

Quienes sostienen que ambos grupos de derechos son igualmente exigibles lo hacen basados en su indivisibilidad e interdependencia. Este argumento parece reflejarse en la práctica de algunos tribunales internacionales de derechos humanos que estando explícitamente autorizados únicamente a conocer reclamos sobre derechos civiles aparentemente también están adjudicando reclamos sobre derechos sociales que -ratione materiae- les serían ajenos ${ }^{3}$. Entre estos órganos jurisdiccionales resalta el Tribunal Europeo de Derechos Humanos (TEDH): el órgano jurisdiccional del Consejo de Europa ubicado en Estrasburgo, que en virtud del Convenio para la Protección de los Derechos Humanos y de las Libertades Fundamentales (CEDH) circunscribe su jurisdicción a un catálogo exclusivo de derechos civiles ${ }^{4}$.

Según Luis López Guerra, juez del TEDH, la jurisprudencia revela que de un tiempo acá ese Tribunal está reconociendo derechos sociales que prima facie estarían fuera de su jurisdicción ${ }^{5}$. Esta afirmación plantea varias cuestiones dignas de estudio. La primera, más cercana al Derecho Constitucional y al Derecho Internacional, es la exigibilidad judicial de los derechos humanos a partir de su indivisibilidad, tanto a nivel conceptual como por la práctica judicial. En otro nivel, la Filosofía del Derecho discute tanto la creatividad interpretativa y los límites a la decisión de los jueces como la teoría de los precedentes judiciales y la forma de entender la jurisprudencia. Finalmente, desde una perspectiva de las teorías de la justicia, se interroga si la distinción entre derechos civiles y derechos sociales "tiene algún sentido, o bien, dicho de otro modo, si existe algún factor que permita justificar la distinción"6.

Para aportar a esta discusión este estudio se centrará en la primera de estas cuestiones, la exigibilidad judicial de los derechos sociales en la práctica judicial del TEDH como tribunal internacional exclusivo de derechos civiles. Examinaremos su caselaw a la luz de un concepto de derechos sociales que distinga el caso central de los casos periféricos. Intentaremos demostrar que no se puede afirmar a secas, y sin matices, que el TEDH está adjudicando derechos sociales. Toda afirmación en este sentido dependerá del concepto de derechos sociales que se utilice, y, más en concreto, del concepto que se identifique como caso central.

\footnotetext{
2 Para propósitos de este estudio, se entenderá que un derecho es exigible judicialmente (o justiciable) cuando un órgano jurisdiccional es competente para (a) conocer y declarar la vulneración de un derecho y (b) formular un mandato de reparación. Abramovich y Courtis (2009) p. 10 entienden justiciabilidad como "la posibilidad de reclamar ante un juez o tribunal de justicia el cumplimiento al menos de algunas de las obligaciones que se derivan del derecho."

3 Confróntese con Bonet Pérez (2016) p. 143. Sobre esta práctica en Latinoamérica véase Soto Velasco (2008) p. 201; Arcidiácono y Gamallo (2017).

4 Confróntese con Jociene (2008) p. 23 y LeijTen (2018) capítulo 1.

Confróntese con López Guerra (2011) p. 11

Abramovich y Courtis (2014) p. 47.
} 


\section{LA DISCUSIÓN GENÉRICA SOBRE LA EXIGIBILIDAD JUDICIAL DE LOS DERECHOS SOCIALES}

A los derechos sociales se les atribuye una suerte de "justiciabilidad débil", ya que aparentemente "no protegen valores tan fundamentales como los civiles y políticos, y tienen una estructura distinta de los derechos subjetivos clásicos"7. De manera que serían solo declaraciones de intenciones y metas a alcanzar por los Estados, pero no tendrían el carácter de supuestos normativos capaces de ser garantizados y exigidos ante los tribunales ${ }^{8}$. Contra su exigibilidad judicial se dice que en las sociedades democráticas debe ser la mayoría representada en el cuerpo legislativo la que determine el contenido de las obligaciones derivadas de la justicia distributiva9 ${ }^{9}$. Comúnmente se objeta la protección judicial de estos derechos aduciendo que se expresan de forma indeterminada y poco precisa; que dar poder a los tribunales para que se pronuncien sobre ellos sería antidemocrático; y que los jueces no están capacitados para adjudicarlos porque para ello deben involucrarse en la toma de decisiones sobre gestión de recursos y prioridades presupuestarias ${ }^{10}$. También se dice que contrario a unas libertades civiles "baratas", los sociales serían derechos "caros"11.

En respuesta se ha dicho que no es exclusiva de los derechos sociales la poca concreción de su contenido, ni la indeterminación de sus obligaciones y que, en cualquier caso, esto no es óbice para su garantía judicial ${ }^{12}$. También se afirma que la distinción entre derechos civiles, como negativos, y derechos sociales, como positivos, no aporta al debate de la exigibilidad pues esta clasificación "no se corresponde con los contenidos de los derechos comprendidos en cada categoría." ${ }^{13}$ más bien, esta categorización binaria ha sido superada por una "ternaria extensible a todos los derechos y que implica una obligación de proteger, de respetar y de realizar" 14 . Contra el argumento democrático se hace notar que la justificación de un sistema de control de justicia constitucional no es tarea sencilla cuando se refiere a derechos sociales, pero tampoco cuando se trata de los civiles y que, por lo tanto, no se puede sustentar que la protección deba ser más intensa en unos que en otros ${ }^{15}$. Finalmente, frente la incapacidad de los jueces para decidir sobre la gestión de recursos se arguye que ellos, en muchos casos, ya resuelven asuntos de relevancia económica y que prácticamente todas las decisiones judiciales tienen consecuencias presupuestarias ${ }^{16}$.

Consideramos que ni los argumentos ni los contraargumentos por sí solos bastan para solventar estas cuestiones complejas y que, además, estas no pueden resolverse al "todo o nada". Por ello, para enriquecer este debate proponemos realizar una aproxima-

\footnotetext{
Mestre i Mestre (2016) p. 117.

Confróntese con Mestre i Mestre (2016) p. 117; Bustos Bottai (2012) p. 136.

Confróntese con Morales (2015) p. 38; Bernal Pulido (2004) pp. 123 y 144.

Confróntese con Gearty (2013) p. 164; Figueroa García-Huidobro (2009-b) p. 589.

Bustos BotTai (2012) p.147.

Confróntese con Mestre i Mestre (2016) p. 123; Bustos Bottai (2012) p. 154.

Morales (2015) p. 80. Véase también Bustos Bottai (2012) p. 138.

Jimena Quesada (2012) p. 136. Confróntese con Bustos Bottai (2012) p. 140.

Confróntese con Pisarello (2007) p. 92; Solari y Vera (2015) p. 47.

Confróntese con Pisarello (2007) p. 95. Figueroa García-Huidobro (2009-b) p. 603: "el estándar de razonabilidad permite a las cortes revisar medidas o decisiones presupuestarias o financieras sin involucrarse en la elaboración de la política presupuestaria o financiera."
} 
ción práctica a la jurisprudencia que ayude a conocer cómo se exigen los derechos sociales en tribunales exclusivos de derechos civiles. Asumimos que independientemente de si los conceptos jurídicos se construyen o se abstraen de manera autónoma -ya sea total o parcialmente-, el uso que de ellos se haga en los tribunales refleja la artificialidad o naturalidad de su construcción. Reconocer la viabilidad práctica de las sistematizaciones doctrinales es especialmente importante en ámbitos como el de los derechos sociales, donde los conceptos son a priori más indeterminados ${ }^{17}$. Por ende, analizar la aplicación que el TEDH hace de los conceptos relacionados con derechos sociales permitirá descubrir si efectivamente adjudica estos derechos y, en caso de hacerlo, si lo hace utilizando los mismos caracteres, matizaciones y grados que identifica la doctrina, o si, por el contrario, utiliza conceptos diversos.

\section{EXIGIBILIDAD DE LOS DERECHOS SOCIALES EN EL TEDH}

En el Consejo de Europa coexisten dos instrumentos separados de derechos humanos con ámbitos de protección y alcance bien delimitados: el CEDH y la Carta Social Europea $(\mathrm{CSE})^{18}$. El primero es un catálogo exclusivo de derechos civiles exigibles mediante demandas individuales ante la jurisdicción del $\mathrm{TEDH}^{19}$. El segundo contiene una relación de derechos sociales supervisados por un órgano no jurisdiccional de expertos independientes (el Comité Europeo de Derechos Sociales) que se encarga de verificar el cumplimiento de las obligaciones asumidas por los Estados parte. A pesar de que desde 1995 la CSE permite a organizaciones no gubernamentales presentar reclamaciones colectivas sobre violaciones estatales, la fiscalización de los derechos sociales permanece en el ámbito político y no judicial ${ }^{20}$. Es decir, actualmente solo los derechos civiles reconocidos en el CEDH cuentan con un mecanismo de protección judicial en el ámbito europeo.

La clara demarcación de los derechos contenidos en estos dos instrumentos incomunicados revelaría que "a primera vista, no hay justiciabilidad de los derechos sociales" en el Consejo de Europa ${ }^{21}$. Sin embargo, en los últimos años el TEDH ha tratado asuntos de índole socioeconómica: recortes de pensiones, contaminación ambiental, provisión de medicamentos y acceso a viviendas estatales ${ }^{22}$. Esto lleva a algunos a proclamar una suerte de socialización del convenio, consistente en dotar a los derechos civiles del CEDH de "un contenido que invade la esfera de los derechos sociales" ${ }^{23}$, gracias a formas de litigio novedosas y a la interpretación creativa del Pacto $^{24}$. A continuación, analizaremos los principales argumentos según los cuales se afirma que el TEDH adjudica derechos sociales a partir de un pacto de derechos civiles.

17 Confróntese con Del Carril (2012) p. 77; Figueroa García-Huidobro (2009-2) p. 593; Bustos Bottai (2012) p. 154

18 No deben confundirse el Consejo de Europa con la Unión Europea. Una clara explicación se puede consultar en: https://www.coe.int /en/web/portal/european-union, visto el 14 de mayo de 2018.

19 Confróntese con Leijten (2018) p. 29.

20 Confróntese con Leijten (2018) p. 31.

21 Nivard (2016) p. 15.

22 LEIJTEN (2018) p. 25.

23 Nivard (2016) p. 16.

24 Confróntese con Mestre i Mestre (2016) p. 113. 
A) El RECONOCIMIENTO DE OBLIGACIONES POSITIVAS

Cada vez es más frecuente condenar a los Estados argumentando que las omisiones de acciones positivas de protección de un derecho civil suponen una forma de violación a los derechos protegidos por el $\mathrm{CEDH}^{25}$. Dado que una característica principal de los derechos sociales es la existencia de obligaciones estatales positivas, constatar que el TEDH condena la omisión de estas acciones confirmaría que sí está adjudicando derechos sociales ${ }^{26}$.

No obstante, este razonamiento no es convincente porque reconocer obligaciones positivas no se traduce directamente en una aceptación llana de los derechos sociales. Cuando el TEDH afirma que "es imposible que un derecho o libertad quede plenamente garantizado sin una acción positiva estatal" ${ }^{27}$, stricto sensu se limita a confirmar que los derechos civiles no llevan el apellido de "negativos" y que de ellos nacen también acciones positivas $^{28}$. Se corrobora, más bien, que de un pacto de derechos civiles se derivan acciones positivas "inherentes al reconocimiento de cualquier derecho" 29.

\section{B) LA PROTECCIÓN MEDIANTE TÉCNICAS DE CONEXIÓN INDIRECTA}

También se comprueba que mediante técnicas no convencionales, o indirectas, el TEDH resuelve reclamaciones sobre seguridad social, salud, vivienda, etc. Puesto que estas técnicas nacen de la práctica en sede litigiosa no es fácil definirlas "si no es, sobre todo, atendiendo a los resultados"30. En líneas generales estas se pueden clasificar de la siguiente forma:

\section{B.1) Conexión con no discriminación}

La primera técnica consiste en establecer una relación entre el derecho social reclamado con la cláusula de no discriminación contenida en el artículo $14 \mathrm{CEDH}^{31}$. Un caso relevante que muestra esta conexión es Stec y otros contra Reino Unido, donde se condenó al Estado a igualar la edad de jubilación para hombres y para mujeres y a modificar la forma de realizar el cálculo de las pensiones ${ }^{32}$.

\section{B.2) Conexión con derechos de procedimiento ${ }^{33}$}

La segunda vía es una "vertiente social de la tutela judicial efectiva" ${ }^{34}$. Por este medio se crea un vínculo entre el derecho social reclamado con la tutela judicial efectiva del $\mathrm{CEDH}$ contenida en los artículos 6 (procedimiento equitativo) y 13 (remedio efectivo). El primer caso que descubre esta conexión es Airey contra Irlanda de 1979, donde se declaró

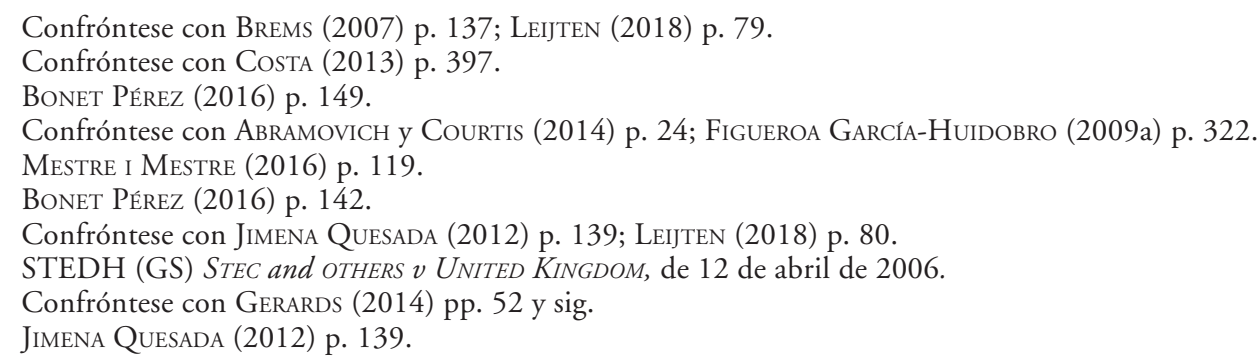


que las barreras socioeconómicas para contratar a un abogado para un juicio de divorcio son interferencias que afectan el contenido del artículo 6 del $\mathrm{CEDH}^{35}$.

Estas dos técnicas no son suficientes para determinar si el TEDH interpreta creativamente el CEDH y reconoce derechos sociales con contenido sustantivo, o si se queda en un simple reconocimiento formal ${ }^{36}$.

\section{B.3) Conexión material con derechos civiles sustantivos}

Esta tercera técnica parece transparentar la interdependencia entre los derechos humanos desde una perspectiva teleológica, que supone que la protección de las libertades civiles no sería posible si se ignoran las implicaciones materiales necesarias para ejercerlas ${ }^{37}$. Por esta vía se daría una suerte de protección sustancial a aquellos derechos no reconocidos expresamente en el CEDH gracias a reconocer una relación intrínseca capaz de crear una vinculación material entre el derecho civil reclamado y el derecho social realmente afectado $^{38}$.

Las reclamaciones en materias de salud, vivienda, seguridad social y trabajo han "revelado interesantes dotes de audacia hermenéutica en el Tribunal de Estrasburgo, dando entrada a situaciones o derechos no cubiertos expresamente por el texto convencional" 39 . Estos litigios supondrían una suerte de incorporación, total o parcial, del derecho social reclamado dentro del contenido esencial del derecho civil recogido en el $\mathrm{CEDH}^{40}$. Con ello se confirmaría que "existe un continuum estructural, de modo que las supuestas diferencias entre ambos no constituyen más que diferencias de grado" ${ }^{41}$.

No obstante, no basta con afirmar que hay un continuum de obligaciones compartidas entre los derechos civiles y los derechos sociales ${ }^{42}$. Es preciso que estas obligaciones sean deducibles lógicamente, reconocibles materialmente y que se deriven de operaciones lícitas de interpretación que tomen en cuenta los límites semánticos y de justicia material que debe respetar el juez ${ }^{43}$. De ahí que profundizar en esta conexión material indirecta $-\mathrm{O}$ conexión implícita- es importante para determinar si efectivamente hay un reconocimiento práctico de la vinculación entre derechos sociales y derechos civiles que dé cuenta de una interdependencia sustancial entre los derechos humanos capaz de ser expresada discursivamente y sistematizada conceptualmente.

Es prudente, por lo tanto, no asumir acríticamente que esta vía de conexión material indirecta conlleva efectivamente un indiscutible reconocimiento de los derechos sociales por parte del TEDH. Por tal razón, examinaremos si Estrasburgo está adjudicando derechos sociales en el caso central o solo en la penumbra.

\footnotetext{
35 STEDH Airey $v$ Ireland, de 9 de octubre de 1979.

Bonet Pérez (2016) p. 158.

Confróntese con Bonet Pérez (2016) p. 173.

Confróntese con Bonet Pérez (2016) pp. 143 y 156.

Jimena Quesada (2012) p. 140; Confróntese con Liejten (2018) p. 58.

Confróntese con Bonet Pérez (2016) p. 156.

Abramovich y Courtis (2014) p. 117.

Confróntese con Bonet Pérez (2016) p. 140.

Confróntese con Zambrano (2009) p. 63.
} 


\section{CASO CENTRAL Y PENUMBRA DE LOS DERECHOS SOCIALES}

La realidad presenta situaciones y casos "frente a los cuales la fertilidad explicativa de los (...) tipos ideales es escasa”, por lo que es ilusorio pensar que la definición de categorías y conceptos jurídicos discurre por "un patrón unívoco de racionalidad" ${ }^{44}$. Conscientes de esto, consideramos que cuestión de la justiciabilidad indirecta de los derechos sociales en el TEDH no es una ecuación de suma cero. Suponemos que si el TEDH adjudica derechos sociales probablemente lo hace solo en su zona de penumbra. Habida cuenta de que el TEDH no hace las mismas distinciones sobre la naturaleza de las obligaciones que sí hace la doctrina, a continuación, ahondaremos en el concepto de derechos sociales para que su precisión semántica nos permita identificar de qué habla el Tribunal cuando usa ese término ${ }^{45}$.

Puesto que la realidad es "más rica, variada, multiforme y contradictoria que las categorías analíticas que inventamos para ordenarla” intuimos que el camino para llegar a un entendimiento sobre la actividad del TEDH cuando resuelve reclamos socioeconómicos discurre por un acuerdo semántico respecto al concepto de derechos sociales ${ }^{46}$. En tal sentido, para saber si el TEDH está imperando sobre derechos sociales primero hace falta "identificar las obligaciones mínimas de los Estados" en relación con estos derechos y luego distinguir los niveles de intensidad de estas obligaciones y, hasta entonces, leer y sistematizar la jurisprudencia ${ }^{47}$. Esta tarea nos resulta fácil porque la estructura de los derechos sociales es distinta de la de los civiles ${ }^{48}$. En la doctrina encontramos diferentes conceptos de derechos sociales, varias formas de clasificarlos y distintas interpretaciones sobre qué es lo mínimo o lo máximo que deben garantizar, ya que "su contenido activo no agota el pasivo" ${ }^{49}$.

Nuestro análisis inicia con la revisión de la estructura de estos derechos y de sus relaciones. De inicio, asumimos que los derechos carecen de "fuerza concluyente hasta que no se traducen en relaciones de tres términos, entre la persona titular; el derecho/objeto/ libertad debido; y la persona obligada" ${ }^{50}$. Un derecho formulado como una relación de dos términos orientada a la cosa -por ejemplo, la persona "A" tiene derecho a la materia o cosa "Z"- para poder reclamarse, también judicialmente, requiere de una enunciación triádica orientada al acto ${ }^{51}$. En los derechos sociales esta estructura tripartita no se circunscribe a identificar el titular del derecho, la prestación concreta grosso modo considerada y el obligado, que es normalmente el Estado ${ }^{52}$. Además, es necesario, en palabras de Finnis, "especificar" el contenido del deber correlativo al derecho, describir los actos propios de su

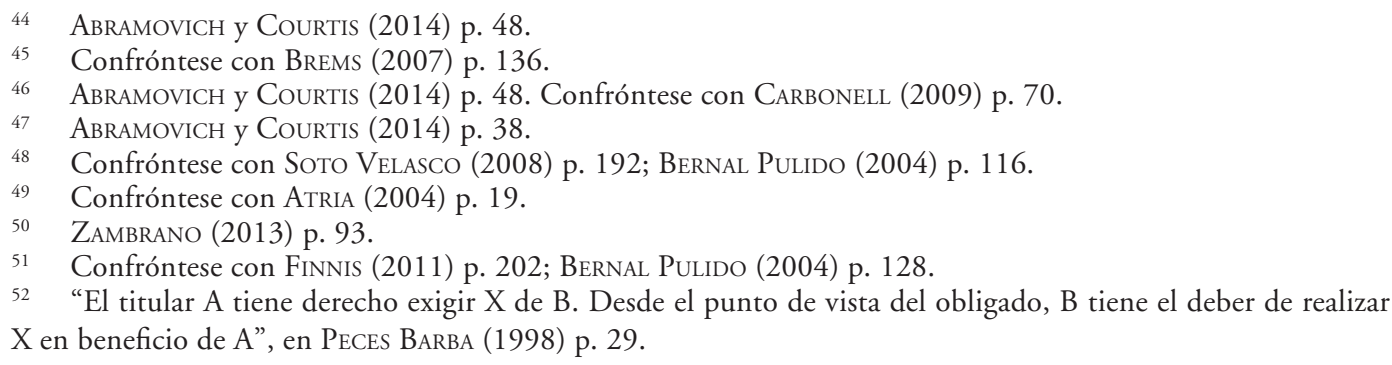


cumplimiento, enumerar las garantías de protección, etc. ${ }^{53}$. Esta definición del contenido adicional sigue el cauce político ${ }^{54}$.

El proceso de especificación de los derechos subjetivos es la razón por la que un mismo concepto genérico (por ejemplo, el derecho social a la salud) puede tener diferentes concepciones ya que, al especificar, la autoridad elige entre un abanico de alternativas igualmente razonables ${ }^{55}$. Analizar un derecho en una relación de dos términos no presenta problemas de reconocimiento, pero examinarlo en una estructura triádica sí plantea retos interpretativos por las diversas formas en que puede concretarse su contenido. Esta precisión, nada ociosa, deja intuir la complejidad de la labor interpretativa de un juez supranacional -como el TEDH- que tiene la tarea de adjudicar derechos con contenido no definido en el pacto constitutivo, ni perfilados en estructura triádica ${ }^{56}$. Un derecho que careciese de especificidad suficiente no sería concluyente y, por ende, vería comprometida su exigibilidad ${ }^{57}$. Es decir, para dotar de exigibilidad a los derechos sociales es imperativo traducirlos al lenguaje de los derechos subjetivos ${ }^{58}$.

El siguiente paso es aclarar cuál es "el contenido exacto del deber" 59 . Este lo encontramos cuando nos preguntamos por el tipo de obligación que supone tal o cual derecho y por el contenido concreto de dicha obligación, así como por "las posiciones del derecho prima facie que pueden ser oponibles al Legislador y a la Administración" ${ }^{60}$. La respuesta a estas preguntas, para ser completa, deberá expresarse en términos que describan los actos específicos, plazos de cumplimiento y otras circunstancias o condiciones que proporcionen una clara identificación del derecho en cuestión ${ }^{61}$.

Al hacernos estas preguntas, de modo genérico descubrimos que los derechos sociales inicialmente "se articulan como derechos de crédito o derechos prestación" ${ }^{62}$ y que tienen forma de "obligaciones de hacer" 63 . Por antonomasia los identificamos con ciertas obligaciones positivas del Estado para aquellos casos en que el individuo es incapaz de proveer para sí mismo, no obstante, esto no significa que no conlleven también otro tipo de obligaciones como la defensa del individuo frente a las intromisiones de terceros que pretendan impedir su propia capacidad de acceder a bienes y servicios ${ }^{64}$.

La clasificación dual entre acciones positivas y acciones negativas es clave para determinar el tipo de obligación principal resultante de los derechos sociales. A pesar de que también se habla de tres tipos de deberes consistentes en respetar, proteger y realizar, consideramos que la división dual de obligaciones sigue vigente pues los deberes de protección y realización son formas de acción positiva ${ }^{65}$. Desde esta perspectiva, identificamos la reali-

Confróntese con Finnis (2011) p. 219.

Confróntese con Morales (2015); Bernal Pulido (2004) p. 123; Martínez Estay (2010) p. 134.

Confróntese con Finnis (2011) p. 219; Bernal Pulido (2004) p. 126.

Confróntese con LeIjTEN (2018) p. 32.

Figueroa García-Huidobro, (2009-a) p. 321.

Confróntese con Atria (2004) p. 39 y 47; Solari y Vera (2015) p. 23.

Zambrano (2013) p. 93.

Confróntese con Bernal Pulido (2004) p. 141.

Confróntese con Finnis (2011) p. 218.

PeCes-Barba (1998) p. 29.

Abramovich y Courtis (2014) p. 24.

Confróntese con Bilchitz (2014) p. 712, 715 y p. 734; Mohor Abuauad (2014) p. 162.

Confróntese con Bilchitz (2014) p. 714; Figueroa García-Huidobro (2009-a) p. 321. 
zación de acciones materiales positivas por parte del Estado como la principal característica de los derechos sociales, mas no la única ${ }^{66}$. Los derechos sociales fundamentales, por ejemplo "los derechos a la asistencia social, al trabajo, la vivienda (...) constituyen un sector importante de aquello que puede denominarse derechos prestacionales, pero no agotan su ámbito" ${ }^{67}$.

Para AleXY, "los derechos a recibir acciones positivas del Estado" serían derechos prestacionales, siempre y cuando el concepto de prestación fuese uno amplio ${ }^{68}$. Las acciones positivas abarcan "un espectro amplio de obligaciones estatales" más allá que el mero dar algo ${ }^{69}$. Incluyen también obligaciones de protección y de procedimiento. En un Estado de Derecho el objeto de una acción positiva material (por ejemplo, el derecho a la seguridad social) presupone la creación de normas y mecanismos que permitan gozar de aquello que se da, que además lo aseguren por medio de un procedimiento efectivo y que garanticen, en todo caso, los derechos de las personas a quienes se les brinda. De esta manera, el concepto amplio de derecho prestacional incluye "la protección del ciudadano frente a otros ciudadanos, por medio de normas del derecho penal, pasa por la creación de normas de organización y procedimiento, y llega hasta prestaciones en dinero y en bienes"70. En otras palabras, el concepto amplio de derecho prestacional sería el de acciones positivas estatales que alcanzan tanto a la provisión de bienes o servicios (prestaciones materiales), como a la creación de legislación y ciertas garantías de procedimiento (prestaciones normativas y fácticas ${ }^{71}$. En definitiva, las acciones positivas en sentido amplio equivaldrían a los derechos prestacionales en sentido amplio, y, en cambio, los derechos prestacionales en sentido estricto, o en su caso central, se identificarían con acciones positivas materiales tangibles.

A partir de la clasificación de AleXY de (a) derechos de protección, (b) derechos de organización y procedimiento y (c) derechos prestacionales en sentido estricto, hemos distinguido cinco niveles de intensidad de los derechos sociales desde la penumbra hasta el caso central, según se explica a continuación ${ }^{72}$ :

Los (a) derechos de protección "son derechos subjetivos constitucionales frente al Estado para que este realice acciones positivas fácticas o normativas que tienen como objeto la delimitación de las esferas de sujetos jurídicos de igual jerarquía, así como la exigibilidad judicial y la implementación de esta delimitación"73. No se trata de meras abstenciones, sino de un hacer en vistas a proteger o promover $\operatorname{algo}^{74}$. En estos derechos de protección encontramos los dos niveles de derechos sociales ubicados en la zona de mayor penumbra: el quinto $\left(5^{\circ}\right)$ nivel, el más alejado del caso central, sería el de las acciones positivas normativas, mientras que el cuarto $\left(4^{\circ}\right)$ nivel sería el de las acciones positivas fácticas. La

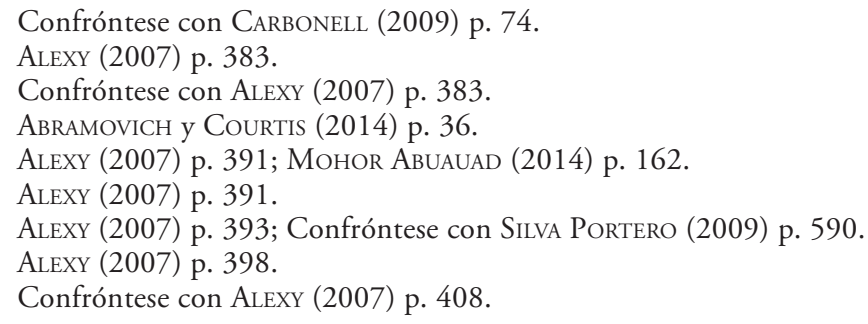


diferencia entre uno y otro radicaría en el mayor grado de cercanía con el modelo típico de derechos civiles, el de la abstención estatal ${ }^{75}$. Las acciones positivas normativas -que identificamos con la creación de normas- es igualmente común e indispensable tanto para los derechos sociales como para los civiles; en cambio, las acciones positivas fácticas -tales como la protección estatal del goce de un derecho por parte del individuo frente a terceros- que implican que el Estado haga algo más allá de solo crear normas está más lejos de la mera abstención ${ }^{76}$.

Los (b) derechos a la organización y al procedimiento se refieren a la creación de normas de procedimiento por la vía legislativa y a la efectiva aplicación de dichas normas por medio de los tribunales de justicia ${ }^{77}$. Los derechos de organización y procedimiento se distinguen de los derechos de protección o acciones positivas -normativas y fácticas- en que no se reducen a la creación de normas sustantivas sobre derechos sociales o la aplicación de medidas fácticas de protección frente a la intromisión de terceros. Se trata más bien de crear un aparato estatal con mecanismos viables de garantía de derechos sociales que permita a los ciudadanos el acceso a los derechos sustantivos consagrados por las normas del quinto $\left(5^{\mathrm{to}}\right)$ nivel de derechos sociales. Ciertamente, las garantías de procedimiento son comunes tanto en materia de derechos civiles como de derechos sociales, pero precisamente por su trascendencia para que los derechos no sean ilusorios las consideramos más intensas que a los derechos de protección y las ubicamos en un nivel intermedio del espectro de derechos sociales, en el tercer $\left(3^{\text {er }}\right)$ nivel ${ }^{78}$.

Finalmente, (c) "los derechos prestacionales en sentido estricto son derechos del individuo frente al Estado a algo que -si el individuo tuviera los medios financieros suficientes, y si encontrase en el mercado una oferta suficiente- podría obtener también de los particulares"79. Los derechos sociales, así concebidos, solo se satisfacen por medio de prestaciones materiales positivas: económicas, aunque no necesariamente monetarias. En este nivel, el titular del derecho social no queda satisfecho con que el Estado se limite a crear normas de protección o a garantizarle el acceso a un procedimiento legislativo o judicial efectivo; quiere y necesita más: una prestación tangible. "Cuando se habla de derechos sociales fundamentales, por ejemplo, del derecho a la seguridad social, al trabajo, la vivienda y la educación, se hace primariamente referencia a derechos prestacionales en sentido estricto" $"$.

Los niveles de mayor intensidad de los derechos sociales los descubrimos en estos derechos prestacionales en sentido estricto. Con todo, es pertinente hacer una ulterior distinción, para distinguir el segundo $\left(2^{\circ}\right)$ y el primer $\left(1^{\mathrm{er}}\right)$ nivel de derechos sociales, fundamentada en el contenido y en la causa que da derecho al titular a reclamar estas prestaciones. Se ha dicho que los derechos sociales en su más alta intensidad implican recibir algo y que es el Estado quien debe proveerlo, pero sigue siendo incierto el porqué de ese derecho, el

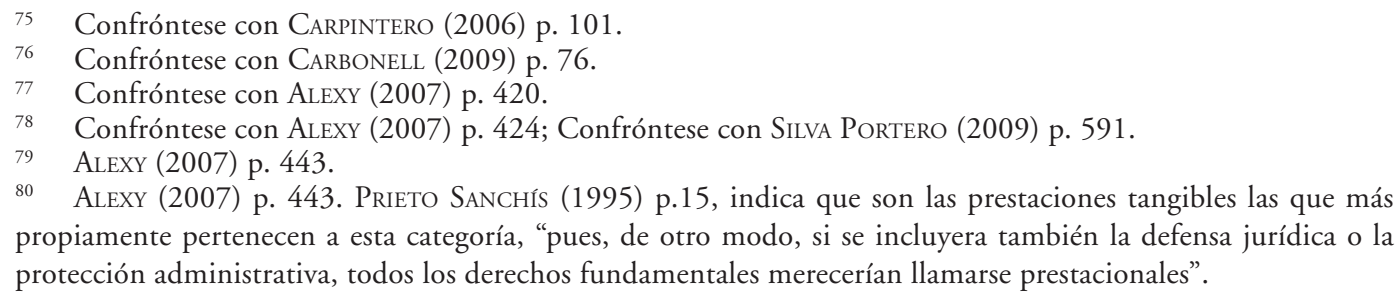


motivo que faculte al titular a reclamar esa prestación estatal. Somos conscientes de que el contenido preciso de cada derecho social no es fácilmente reconocible debido a la indeterminación de su contenido específico ${ }^{81}$. A pesar de eso, a continuación, intentaremos distinguir el caso central del segundo $\left(2^{\circ}\right)$ nivel de derechos sociales.

Por un lado, ciertos autores limitan los derechos sociales a la satisfacción de las necesidades básicas en un nivel de subsistencia, cosa que parecería acertada para los países en vías de desarrollo donde el escenario de pobreza o desigualdad es acuciante ${ }^{82}$. Esta concepción, más cercana a la tradición liberal, plantea los derechos sociales como un mínimo para resolver situaciones de desigualdad. Por ejemplo, Cécile Fabre propone un mínimo social para llevar una vida decente; es decir, como un cúmulo de recursos, prestaciones en efectivo, bienes o servicios que satisfagan de forma mínimamente suficiente tres intereses humanos centrales: (a) el bienestar, (b) la autonomía; y (c) la participación en sociedad ${ }^{83}$. King, por su parte, indica que el contenido de estos derechos deberá determinarse por las exigencias de libertad o autonomía, en el sentido de que para poder ser libres es necesario contar con medios materiales suficientes que hagan posible al individuo no sujetarse al control de otros y, a la vez, ser capaz de comprender las complejidades de la vida política y participar plenamente en sociedad ${ }^{84}$.

Por otro lado, hay autores más cercanos a la tradición socialista que defienden que los derechos prestacionales deben satisfacer las necesidades materiales de las personas from craddle to grave por el simple hecho de pertenecer a la comunidad política ${ }^{85}$. Esta forma de pensar los derechos sociales es más propia de los países desarrollados, donde el nivel de vida de los individuos excede cualquier tipo de mínimo social ${ }^{86}$. Una visión maximalista de los derechos sociales prestacionales como esta no tomaría en cuenta las condiciones de precariedad de las personas para merecer un derecho social. Por ejemplo, este sería el caso de quien al cumplir la edad de jubilación reclama su pensión de seguridad social sin consideración de su posición socioeconómica, de sus ahorros o de otras fuentes de ingresos.

Como vemos, en general, todas las visiones del contenido esencial de los derechos sociales prestacionales acentúan su carácter indeterminado debido a factores económicos y sociales ${ }^{87}$. No obstante, se posicionan en dos niveles claramente distintos: (a) o en un mínimo necesario que satisfaga ciertos intereses humanos centrales: subsistencia, participación social y autonomía; o (b) en un desarrollo pleno, generalizable a cualquiera, sin consideración de la condición de subsistencia. En estas dos posiciones hemos distinguido los últimos y más agudos niveles de intensidad de los derechos sociales. El primer $\left(1^{\mathrm{er}}\right)$ nivel de intensidad, el caso central, sería la prestación material en sentido estricto para un desarrollo pleno sin consideración de un mínimo social, es decir, los derechos sociales más propios de una tradición socialista. El segundo $\left(2^{\circ}\right)$ nivel de intensidad se identificaría con

Confróntese con Martínez Estay (2010) p. 160; Alexy (2007) p. 450.

Confróntese con Morales (2015) p. 189.

Confróntese con KING (2012) p. 29.

Confróntese con King (2012) p. 24; AleXy (2007) p. 446.

Confróntese con Atria (2004) p. 30.

Confróntese con Bilchitz (2014) p. 732.

Confróntese con KING (2012) pp. 29 y 33. 
la prestación material en sentido estricto en consideración de un mínimo social, es decir los más próximos a la visión más liberal. La diferencia, sutil, entre ambos niveles radica en la consideración del porqué del otorgamiento de la prestación.

Resumiendo lo dicho hasta aquí, el análisis doctrinal nos ha permitido identificar cinco niveles de intensidad de los derechos sociales, partiendo desde el caso central hacia la penumbra, de la siguiente manera:

1) El caso central, o primer nivel, se identifica con las prestaciones materiales en sentido estricto per se, generalizables a todos los individuos sin consideración de una condición de subsistencia o necesidad apremiante.

2) El segundo nivel es el de las prestaciones materiales en sentido estricto en atención a un mínimo social determinado para cada comunidad.

3) El tercer nivel es el de las acciones de organización y procedimiento.

4) El cuarto nivel es el de las acciones positivas fácticas de protección.

5) El quinto nivel es el de las acciones positivas normativas.

Hasta este momento hemos analizado los derechos sociales tomando en cuenta principalmente las obligaciones positivas del Estado, es decir, aquellas en las que este debe hacer o garantizar algo a favor del individuo, ya sea un bien o servicio tangible, un procedimiento o cierta legislación, etc. Queda claro que la visión de los derechos sociales exclusivamente como obligaciones positivas es errónea y que todos los derechos comparten obligaciones tanto positivas como negativas ${ }^{88}$. Así, por ejemplo, la obligación negativa de garantizar al individuo el acceso a bienes socioeconómicos requiere la acción positiva del Estado de proteger ${ }^{89}$.

Los derechos sociales también deben ser protegidos negativamente frente a intromisiones indebidas ${ }^{90}$. Este deber de no intervención, que es más propio de los derechos civiles, tiene una doble manifestación ${ }^{91}$. Por un lado, se refiere a la obligación de no intervención del propio Estado y, por otro, a que el Estado garantice la no interferencia de terceros en las posesiones de cada individuo. La primera tiene la forma de obligación negativa en sentido estricto o "protección negativa", y la segunda es una obligación positiva o "protección positiva" 92 . Reluce entonces que hay "una coincidencia estructural" en la forma de configurarse el deber de no intervención para garantizar un derecho civil y la configuración de esta misma protección sobre "un derecho prestacional, tal como el derecho a recibir subvenciones" ${ }^{\prime 3}$. Esta coincidencia, que se observa diáfana en el caso de la no intervención, amerita un análisis sucinto del objeto de los derechos civiles con el fin de descubrir también su caso central y su penumbra y así valorar mejor la imbricación entre los dos grupos de derechos en los niveles más elementales. Todo esto iluminará nuestra comprensión de la actividad judicial del TEDH.

\footnotetext{
88 Confróntese con Bilchitz (2014) p. 714.

89 Confróntese con Bilchitz (2014) p. 722.

90 Confróntese con Bilchitz (2014) p. 714.

91 Confróntese con AleXy (2007) p. 166.

92 "El derecho a la no obstaculización es un derecho a una acción negativa”. AleXY (2007) p. 200. "Una protección positiva de una libertad frente al Estado surge mediante la combinación de una libertad con un derecho a una acción positiva” AleXY (2007) p. 201.

93 AleXy (2007) p. 201.
} 
Una primera observación, respecto al objeto de los derechos civiles, es que se presentan como "derechos del ciudadano frente al Estado a acciones negativas" de este último ${ }^{94}$. Tradicionalmente han sido considerados, por antonomasia, como libertades o derechos negativos que incluyen (a) derechos al no impedimento de acciones; (b) derechos a la no afectación de propiedades y situaciones; (c) derechos a la no eliminación de situaciones jurídicas ${ }^{95}$.

Asumiremos que el caso central de los derechos civiles es el no impedimento de acciones, en el sentido que el individuo tiene el derecho a que el Estado no le haga fácticamente imposible realizar las acciones a que tiene derecho ${ }^{96}$. Más allá, en dirección a la zona de penumbra, se encuentran tanto la no afectación de propiedades y situaciones, como la no eliminación de situaciones jurídicas. La distinción entre estas y el caso central radica en que en este último el impedimento es fáctico, en cambio en los otros es jurídico. El caso central de los derechos civiles reclama una abstención total a nivel fáctico; en cambio, en los casos más cercanos a la penumbra, el derecho del individuo exige también que la actividad positiva estatal, como la creación legislativa, no suponga derogaciones implícitas de los derechos o no afecte indirectamente sus propiedades o situaciones jurídicas. "Al derecho a la no eliminación, en cuanto derecho a una acción negativa, corresponde siempre un derecho a mantener en vigencia la norma, que siempre es un derecho a una acción positiva" ${ }^{97}$. Finalmente, en la penumbra de los derechos civiles encontraríamos los derechos a acciones positivas normativas, es decir, "los derechos a actos estatales de creación de normas" 98 .

Una traducción gráfica del espectro de los derechos sociales y de los derechos civiles mostraría más o menos una conjunción de dos grupos concéntricos que en cada extremo agruparían a los respectivos casos centrales. Luego, en un movimiento de intensidad decreciente llegarían a los niveles más periféricos y culminarían en un punto de entrecruzamiento de los niveles más elementales de ambos tipos de derechos donde las obligaciones positivas y negativas serían prácticamente compartidas.

\section{REVISIÓN DE LA JURISPRUDENCIA DEL TEDH}

Tras el análisis del concepto de derechos sociales desde la perspectiva del caso central y de los casos de la penumbra, procederemos a revisar el caselaw del TEDH. La enjundia de nuestra propuesta es un análisis profundo de la argumentación del TEDH y su interpretación a la luz de la identificación del caso central de los derechos sociales. Todos los casos analizados son recientes, pues nos interesa evaluar la actual forma de resolver del Tribunal. Además, todos han sido citados por estudios doctrinales sobre la materia y son presentados por la doctrina como ejemplos claros de que en Estrasburgo se están adjudicando derechos sociales. Finalmente, como ya hemos anticipado, puesto que nos interesa estudiar

\footnotetext{
$94 \quad$ Alexy (2007) pp. 165.

95 Confróntese con AleXY (2007) pp. 165 y sig.

96 Hay una diferencia entre impedimento y obstaculización. El primero es de carácter fáctico, y más intenso, y, en cambio, el segundo es de tipo jurídico y menos intenso. Confróntese con AleXY (2007) p. 166.

$97 \quad$ Ver nota al pie 72 en AleXY (2007) p. 171.

98 AleXY (2007) p. 171.
} 
únicamente la conexión indirecta material entre derechos sociales y derechos civiles hemos prescindido de aquellos casos, aunque sean citados también por la doctrina, donde el motivo de la adjudicación sea la no discriminación (art. 14) o la tutela judicial efectiva (arts. 6 y 13) del $\mathrm{CEDH}^{99}$.

Nuestro análisis de las sentencias identifica principalmente el bien protegido por el Tribunal y la conducta que se impone al Estado como medida de reparación (imperio). El bien protegido y el imperio son reflejo del tipo de obligación y del derecho adjudicados. También, tangencialmente, nos interesa ver si el TEDH realiza un juicio de proporcionalidad para fundamentar su decisión, en el sentido de que si es este Tribunal quien hace el balance de los derechos sociales en juego o si encomienda esta labor a cada Estado ${ }^{100}$.

\section{a) VIVIENDA EN CONEXIÓN CON VIDA PRIVADA Y FAMILIAR Y CON DOMICILIO}

Sobre esta conexión analizaremos tres sentencias. La primera es del caso McCann contra Reino Unido de mayo de 2008. Se trata de un inquilino que era cotenedor en régimen especial de una vivienda familiar propiedad del Birmingham City Council. Por violencia doméstica se separó de su cónyuge, con quien compartía la tenencia. Tras la separación, y habiéndose mudado la mujer y los hijos a otra casa, la autoridad local inició un procedimiento abreviado de desahucio para lo cual obtuvo de su ex esposa el consentimiento suficiente que terminaba el contrato para ambos tenedores. El peticionario alega que el desahucio supuso una intervención ilegítima en su intimidad familiar porque no se informó adecuadamente a la mujer de las consecuencias legales del documento de terminación de la tenencia. El TEDH señala unánime que ha habido una violación al artículo 8 del CEDH. Leijten propone este caso como un ejemplo de que la violación a un procedimiento sirve para proteger las necesidades sustantivas mínimas del peticionario, asegurando así un estándar socioeconómico básico sin interferir indebidamente con las políticas nacionales ${ }^{101}$. Sin embargo, nuestro análisis nos sugiere matizar dicha afirmación.

Comienza argumentando el TEDH que la pérdida de la vivienda es una forma extrema de interferencia en el derecho al domicilio ${ }^{102}$. Establece que cualquier persona en este riesgo debe tener la posibilidad de revisión de la proporcionalidad de la medida por un tribunal independiente a la luz del artículo 8 del $\mathrm{CEDH}^{103}$. La falta de este procedimiento

99 La diferencia principal entre la tutela judicial efectiva (artículos 6 y 13 del CEDH) y las acciones de organización y de procedimiento que identificamos como tercer $\left(3^{\text {er }}\right)$ nivel de derechos sociales radica en el petitorio que se hace al Tribunal con la demanda. Cuando ante el TEDH se reclama una violación al artículo 6 del CEDH estamos frente a la tutela judicial efectiva del convenio, en cambio, cuando el Tribunal resuelve indicando que el Estado no otorgó garantías procedimentales para el goce de los derechos sin hacer mención a dicho artículo ni en el petitorio ni la resolución, estamos frente a un tercer $\left(3^{\text {er }}\right)$ nivel de derechos sociales.

100 El juicio de proporcionalidad muestra si el TEDH dirige su análisis sobre un derecho civil o si se fija más detenidamente en los derechos sociales involucrados, pues "la garantía del contenido esencial es una exigencia de la faz negativa de los derechos, en tanto que el principio de razonabilidad viene exigido por la faz positiva o prestacional", en CIANCIARDO (2009) p. 114. Si el TEDH hiciese un análisis de proporcionalidad de los intereses protegidos por los derechos sociales probablemente sí los estaría adjudicando.

101 Confróntese con Ruiz Albert (2015) y Leijten (2018) p. 237.

102 Confróntese con STEDH MCCANN v. THE UNITED KINGDOM, de 13 de mayo de $2008 \$ 50$.

103 Confróntese con STEDH MCCANN v. THE UNITED KINGDOM, de 13 de mayo de $2008 \$ 50$ y 51 . 
supone una violación al artículo 8 en su aspecto procedimental ${ }^{104}$. Este argumento sitúa el bien protegido en la penumbra de los derechos sociales, es decir, en el tercer $\left(3^{\text {er }}\right)$ nivel de acciones de procedimiento. El Tribunal en ningún momento indica que el peticionario tiene derecho a una vivienda por sí misma (caso central) o que el desahucio compromete su subsistencia. Se atreve a decir, incluso, que probablemente un tribunal independiente hubiese confirmado el desahucio basado en los antecedentes de violencia doméstica y en la situación de escasez de vivienda ${ }^{105}$. El imperio también revela el nivel en que se mueve el Tribunal, pues de los 77.750,00 EUR de indemnización, 75.000 EUR corresponden a costos asociados a los procedimientos judiciales tanto en Reino Unido como en Estrasburgo y no a proveer una nueva vivienda al peticionario.

El segundo caso es Škrtic contra Croacia de diciembre de 2013. Se trata de una peticionaria a quien en el año 2000 la autoridad municipal le ordenó desalojar una casa de la que era mera tenedora. En 2008, el juzgado municipal confirmó la orden de desalojo, pues la ocupación de la vivienda se había otorgado de forma temporal a su ex marido, quien ya no residía ahí. Al momento de la sentencia, el desalojo no se había consumado. El TEDH condena al Estado por violación al artículo 8 del CEDH. Ruiz Albert propone este caso, entre varios, como reflejo de que la interdependencia de los derechos humanos ha llevado al TEDH a no quedar al margen de la protección ante los desalojos forzosos susceptibles de dejar personas sin hogar ${ }^{106}$. Nuestro análisis, enfocado en la distinción entre caso central y penumbra, nos lleva a concluir que el TEDH no protege a las personas desahuciadas por el hecho de serlo, sino que garantiza que las personas que serán desahuciadas sigan un procedimiento judicial con estándares mínimos de justicia.

Siguiendo su línea jurisprudencial, Estrasburgo reiteró que cualquier persona en riesgo de sufrir una interferencia en su derecho al domicilio debe tener la posibilidad de que un tribunal independiente evalúe la proporcionalidad de la medida bajo el artículo 8 del $\mathrm{CEDH}^{107}$. Los jueces nacionales, apunta el Tribunal, se limitaron a determinar la legalidad de la ocupación de la peticionaria sin fijarse si la medida era proporcionada, máxime porque ella ocupaba el inmueble desde $1991^{108}$. Según el TEDH, los derechos en juego son, por un lado, la reivindicación del dominio de la autoridad propietaria del inmueble y el respeto al domicilio de la peticionaria ${ }^{109}$. El TEDH exige, que la medida para proteger el derecho de propiedad estatal debe ser razonable y en este caso parece que no lo es, o que dicha evaluación no se hizo a nivel local ${ }^{110}$.

El razonamiento principal en que se apoya el TEDH es que no hay intereses de otros particulares en juego, únicamente el interés legítimo del Estado en controlar su propiedad, mismo que deviene en un segundo plano respecto al derecho de la peticionaria a que se respete su domicilio ${ }^{111}$. Esto ubica nuevamente el bien protegido en un tercer $\left(3^{\text {er }}\right)$ nivel de

\footnotetext{
104 Confróntese con STEDH MCCANN v. THE UNITED KINGDOM, de 13 de mayo de $2008 \$ \$ 55$ y 59.

105 Confróntese con STEDH MCCANN v. THE UNITED KINGDOM, de 13 de mayo de $2008 \$ 59$.

106 Confróntese con Ruiz Albert (2015) p. 171.

107 Confróntese con STEDH ŠKRTIC v. CROATIA, de 5 de diciembre de $2013 \$ 31$.

108 Confróntese con STEDH ŠKRTIC v. CROATIA, de 5 de diciembre de $2013 \$ 35$.

109 Confróntese con STEDH ŠKRTIC v. CROATIA, de 5 de diciembre de 2013 \$\$ 27 y 29.

110 Confróntese con STEDH ŠKRTIC v. CROATIA, de 5 de diciembre de $2013 \$ 34$.

111 Confróntese con STEDH ŠKRTIC v. CROATIA, de 5 de diciembre de $2013 \$ \$ 34$ y 35.
} 
derechos sociales. También es significativo que el Tribunal únicamente condena al Estado a pagar 3.000,00 EUR como indemnización por el daño moral y en ningún momento exige que se le dé una casa a la señora.

El tercer caso es el de Ivanova y Cherkezov contra Bulgaria, resuelto en abril de 2016. Se trata de unos cónyuges que adquirieron por herencia el $77.5 \%$ de un inmueble. La propiedad del resto del inmueble la compartían con diez hermanos de la esposa. Los peticionarios hicieron reparaciones en una vivienda ubicada en dicha propiedad y la convirtieron en su casa. Estas reparaciones, costeadas totalmente por ellos, no fueron autorizadas por la municipalidad, por lo que esta ordenó la demolición de la vivienda, siguiendo el protocolo previsto por la ley para casos de construcciones no autorizadas. Dicha orden fue confirmada por los tribunales, aunque aún no se ha llevado a cabo. El TEDH nuevamente condenó por violación al artículo 8 del CEDH. Bouazza utiliza este caso para ejemplificar cómo los conceptos de sostenibilidad y calidad de vida en el ámbito europeo han favorecido la sensibilización y evolución del Tribunal de Estrasburgo hacia lo social ${ }^{112}$. No obstante, nuestro análisis nuevamente nos lleva a matizar esta conclusión.

El Tribunal comienza reiterando que la pérdida de la vivienda constituye una de las interferencias más extremas al respeto por el domicilio, de forma que cualquier persona en riesgo de sufrir una medida de este tipo necesita que se revise la proporcionalidad de esta por un tribunal independiente a la luz del artículo 8 del $\mathrm{CEDH}^{113}$. También señala, obiter dictum, que el interés público de lograr la efectiva aplicación de la regulación urbanística no es razón suficiente para demoler la vivienda de una persona ${ }^{114}$. A pesar de esto último, nos parece que el Tribunal no pasa de un tercer $\left(3^{\text {er }}\right)$ nivel de derechos sociales porque la condena se basa en la omisión de las garantías de procedimiento necesarias para verificar la proporcionalidad de la medida bajo el artículo 8 del $\mathrm{CEDH}$, en una revisión caso por caso y a la luz de las circunstancias personales de cada uno ${ }^{115}$. Es llamativo, que a pesar del hecho de que se trata de la única vivienda de los peticionarios la resolución de violación del artículo 8 solo va acompañada de una indemnización de 2.013,73 EUR por daño moral.

b) VIVIENDA EN CONEXIÓN CON PROHIBICIÓN DE TORTURA, CON VIDA PRIVADA Y FAMILIAR Y CON DOMICILIO

El 13 de octubre de 2016, el TEDH resolvió Irina Smirnova contra Ucrania. Se trata de una madre soltera y jubilada que es copropietaria, conjuntamente con su hijo, de una vivienda en partes iguales. En 2001, el hijo donó el 100\% de su parte a un tercero, desconocido de su madre, que pasó a ser el nuevo copropietario. Desde entonces, este tercero hostigaba a la peticionaria a que le transfiriese el $100 \%$ de su parte por un precio muy inferior al valor real (casi USD 700). La peticionaria se negó y, a causa de ello, fue objeto de maltrato físico y psíquico durante años. Temiendo por su integridad y su vida abandonó el inmueble y siguió sin éxito sendos procesos, civil y penal, contra los agresores. En 2014, el

112 Confróntese con BouazZa Ariño (2017) p. 83.

113 Confróntese con STEDH IVANOVA and CHERKEZOV v BULGARIA, de 21 de abril de $2016 \$ 53$.

114 Confróntese con STEDH IVANOVA and CHERKEZOV v BULGARIA, de 21 de abril de $2016 \$ 54$

115 Confróntese con STEDH IVANOVA and CHERKEZOV v BULGARIA, de 21 de abril de $2016 \$ \$ 54$ y 61. 
copropietario fue condenado penalmente por extorsión. El Tribunal resolvió este caso en base a la prohibición de tortura y a la vida privada y familiar, y condenó al Estado. Gerards ve aquí una demostración de que los derechos del $\mathrm{CEDH}$ llevan aparejados obligaciones positivas de protección material ${ }^{116}$.

Con respecto a la prohibición de tortura, se estableció que para los efectos del artículo 3 del $\mathrm{CEDH}$, las medidas de protección exigen que las autoridades respondan con particular urgencia y de forma proporcionada al riesgo potencial al que se ve sometida una persona dentro de un plazo razonable y aun cuando los malos tratos provienen de particulares ${ }^{117}$. La situación es más grave porque es una madre soltera jubilada y porque los malos tratos se prolongaron durante años y las autoridades no reaccionaran eficazmente. Aunque el Tribunal dice que las autoridades en un inicio pudieron haber tenido dificultades en tipificar la confrontación entre la peticionaria y el copropietario, no se justifica un retraso de doce años ${ }^{118}$. Nos parece que, con respecto a la prohibición de tortura, el bien protegido por el Tribunal se queda en un cuarto $\left(4^{\circ}\right)$ nivel de derechos sociales: el de las acciones positivas fácticas, en este caso, la acción de la autoridad para garantizar el derecho al domicilio.

En relación con la vida privada y familiar, artículo 8 del $\mathrm{CEDH}$, se exige un nivel aceptable de protección frente a las intromisiones de terceros en la privacidad y en el disfrute del domicilio, por ejemplo, a través de normativa sustantiva que regule la cohabitación no deseada y con normas adjetivas al estilo de las medidas cautelares ${ }^{119}$. Ya que compartir la vivienda con personas extrañas supone serias implicaciones a la privacidad es necesario establecer un abanico de remedios oportunos por la vía de regulación y de garantías procedimentales para evitar estas situaciones ${ }^{120}$. Como vemos, el TEDH está hablando de normas que protejan el derecho a la vida privada en aquellos casos de cohabitación no consentida y gravosa ${ }^{121}$. Estos argumentos manifiestan que el bien protegido se queda en el quinto $\left(5^{\circ}\right)$ nivel de intensidad de derechos sociales, el de acciones normativas.

Por su parte, el que la condena se limite a una indemnización de 4.000,00 EUR a pesar de que la peticionaria pedía que el gobierno le comprase una nueva casa, manifiesta claramente que no hay una correlación entre las violaciones encontradas con la necesidad de financiar la adquisición de una vivienda ${ }^{122}$.

\section{c) SALUd en CONEXión CON El RESPETO a la VidA}

En 2011 el TEDH resolvió el caso Trzepalko contra Polonia sobre el reclamo de un padre cuya hija murió contaminada por estreptococo en un hospital. Tras un procedimiento criminal por homicidio se determinó que no hubo responsabilidad del hospital en la transmisión de la bacteria ${ }^{123}$. A pesar de que el TEDH declaró inadmisible la petición,

\footnotetext{
116 Confróntese con Gerards (2018) p. 143.

117 Confróntese con STEDH IRINA SMIRNOVA v. UKRAINE, de 13 de octubre de $2016 \$ \$ 70$ y 75.

118 Confróntese con STEDH IRINA SMIRNOVA v. UKRAINE, de 13 de octubre de $2016 \$ 76$.

119 Confróntese con STEDH IRINA SMIRNOVA v. UKRAINE, de 13 de octubre de $2016 \$ \$ 92$ y 95.

120 Confróntese con STEDH IRINA SMIRNOVA v. UKRAINE, de 13 de octubre de $2016 \$ 94$.

121 Confróntese con STEDH IRINA SMIRNOVA v. UKRAINE, de 13 de octubre de $2016 \$ 97$.

122 Confróntese con STEDH IRINA SMIRNOVA v. UKRAINE, de 13 de octubre de $2016 \$ 108$.

123 Confróntese con STEDH TRZEPALKO v POLAND, de 13 de septiembre de $2011 \S 28$.
} 
para Schabas, este caso manifiesta que las obligaciones positivas derivadas del artículo 2 del $\mathrm{CEDH}$ se concretan en la esfera de la sanidad pública, en particular, en la responsabilidad del Estado por acciones y omisiones en su política sanitaria ${ }^{124}$.

La resolución del Tribunal se basó en que la obligación procedimental exigida por el derecho a la vida se considera cumplida al implementarse un sistema judicial independiente capaz de determinar y exigir responsabilidad a los profesionales sanitarios en caso del fallecimiento de sus pacientes ${ }^{125}$. El Tribunal no exige a los Estados que brinden prestaciones materiales concretas, tales como pensiones por fallecimiento o que reparen de alguna forma a las víctimas por negligencia médica o culpa, le basta con que se cumplan las garantías de procedimiento, que en este caso sí se cumplieron porque Polonia dispone de un sistema judicial aceptable a juicio del Tribunal y más bien fueron los peticionarios quienes erraron el camino a ir por la vía criminal en lugar de buscar una reparación civil. Esto nos hace pensar, una vez más, que el bien protegido está en el tercer $\left(3^{\text {er }}\right)$ nivel de intensidad de los derechos sociales.

Otro caso que presenta esta misma conexión es Wiater contra Polonia. En mayo de 2012 el TEDH confirmó que no hay ningún derecho a tener acceso a tratamiento médico gratuito y que el margen de apreciación del Estado es amplio al determinar las prioridades de asignación de recursos escasos ${ }^{126}$. Se trata de un peticionario que al ser diagnosticado con narcolepsia en 1977 y luego con hepatitis B exige del Estado la provisión de un medicamento que estima necesario para salvar su vida. El Estado rechaza su solicitud pues ese medicamento no se contempla en el listado oficial de fármacos proveídos por la sanidad pública. Unánimemente el TEDH declaró que, aunque sería deseable que todos tuviesen acceso a tratamientos médicos y fármacos, desafortunadamente la escasez de recursos lo hace imposible ${ }^{127}$. Por lo tanto, que no se financie la salud no puede considerarse como una violación contra el derecho a la vida ${ }^{128}$. Con este argumento el TEDH rechaza el segundo nivel de derechos sociales. Continúa el TEDH diciendo que el criterio para determinar si un Estado pone en riesgo la vida de un individuo, es si injustificadamente se niega a brindar un tratamiento médico al que se hubiese comprometido legalmente ${ }^{129}$. Consideramos que el TEDH se ubica en un cuarto $\left(4^{\mathrm{t}}\right)$ nivel de intensidad derechos sociales, el de las acciones fácticas de protección.

Comentando este caso, Rieder apunta que la inadmisión del tribunal se fundamenta en que no existe obligación estatal de financiar tratamientos médicos particulares. No obstante, señala que el rechazo del tribunal se debe principalmente a que el peticionario solicitó la protección según el artículo 2 del $\mathrm{CEDH}$, derecho a la vida, por dos enfermedades que no constituyen serio peligro de muerte: hepatitis B y narcolepsia, abriendo la puerta a que de reclamarse otro derecho quizá si hubiese tenido éxito, o a que si las enfermedades fuesen realmente mortales el Estado quizá tuviese responsabilidad ${ }^{130}$.

124 Confróntese con Schabas (2015) p. 131.

125 Confróntese con STEDH TRZEPALKO v POLAND, de 13 de septiembre de $2011 \$ 25$.

126 Confróntese con STEDH WIATER v POLAND, de 15 de mayo de $2012 \$ 36$.

127 Confróntese con STEDH WIATER v POLAND, de 15 de mayo de $2012 \$ 36$.

128 Confróntese con STEDH WIATER v POLAND, de 15 de mayo de $2012 \$ 38$.

129 Confróntese con STEDH WIATER $v$ POLAND, de 15 de mayo de $2012 \$ 35$.

130 Confróntese con Volou (2017) y Rieder (2015) p. 96. 


\section{d) Seguridad SOCIAL EN CONEXión CON DERECHO DE PROPIEDAD}

A finales de 2016 se resolvió el caso Béláné Nagy contra Hungría. En una apretada decisión de 9 contra 8, la Gran Cámara declaró la violación del artículo 1 del protocolo 1 y condenó al Estado a indemnizar a la peticionaria con 27.795,01 EUR. Al respecto, dice Leijten que esta sentencia puede leerse como el reconocimiento del derecho a un mínimo de beneficios sociales resultantes de la protección del derecho de propiedad, independientemente del cumplimiento de los requisitos exigidos por la legislación local ${ }^{131}$. Nos parece que esta afirmación también puede matizarse a la luz del caso central y de la penumbra de los derechos sociales.

Se trata de una mujer que fue privada de su pensión de invalidez debido a dos cambios legislativos. Una primera ley, en 2010, modificó la forma de cálculo de incapacidad física disminuyendo su grado de invalidez de un $67 \%$ a un $40 \%$. Con ello la peticionaria perdió automáticamente el derecho a la pensión de incapacidad, que solo podría recuperar si su invalidez aumentaba a, al menos, 50\%. Sin embargo, la peticionaria no pudo reingresar al sistema a pesar de que una nueva evaluación le asignaba una invalidez del $50 \%$ en 2011, pues una ley de 2012 modificó retroactivamente los requisitos para gozar cualquier tipo de pensiones. Según esta nueva ley, solo obtendrían beneficios quienes estuviesen recibiendo una pensión en ese momento o hubiesen cotizado por cierto período, condiciones que ella no cumplía.

El TEDH sostiene que las contribuciones a un fondo de pensiones en ciertos casos pueden crear derechos de propiedad ${ }^{132}$. Si el Estado ha puesto en vigor una legislación que provee el pago de algún beneficio social, dicha legislación debe considerarse como creadora de intereses de propiedad y por tanto protegidos por el artículo 1 del protocolo $1^{133}$. Los argumentos del TEDH en esta sentencia son confusos ${ }^{134}$. A veces parece ubicar a la seguridad social en un segundo $\left(2^{\circ}\right)$ nivel de derechos sociales, por ejemplo, cuando afirma que en la sociedad democrática actual muchos individuos dependen de los beneficios sociales para sobrevivir ${ }^{135}$. También cuando dice que la privación de la totalidad de la pensión podría considerarse una violación a los derechos derivados del artículo 1 del protocolo 1 y que, en cambio, reducciones razonables de los beneficios probablemente no lo serían ${ }^{136}$. Incluso cuando indica que la peticionaria fue sujeta a una completa privación de cualquier beneficio, en lugar de a una reducción adecuada y que, además, no tenía ninguna otra fuente suficiente de ingresos para subsistir ${ }^{137}$. En su conjunto parecería que el TEDH asume que la seguridad social es un tipo de prestación material necesaria para garantizar la subsistencia.

Sin embargo, no es así. Por un lado, porque el TEDH respeta un amplio margen de apreciación nacional para establecer o no un sistema de seguridad social, para definir el monto o tipo de beneficios que se provean bajo ese esquema, y para modificar dicho siste-

Cfr Leijten (2018) p. 289.

Confróntese con STEDH (GS) BÉLANÉ NAGY v HUNGARY, de 13 de diciembre de $2016 \$ 81$.

Confróntese con STEDH (GS) BÉLANÉ NAGY v HUNGARY, de 13 de diciembre de $2016 \$ 82$.

Confróntese con LeijTEN (2013).

Confróntese con STEDH (GS) BÉLANÉ NAGY v HUNGARY, de 13 de diciembre de $2016 \$ 80$.

Confróntese con STEDH (GS) BÉLANE NAGY v HUNGARY, de 13 de diciembre de $2016 \$ 117$.

Confróntese con STEDH (GS) BÉLANÉ NAGY v HUNGARY, de 13 de diciembre de $2016 \$ 123$. 
ma por motivos sociales o económicos ${ }^{138}$. Por otro, porque vuelve a poner el acento en las garantías de procedimiento. Afirma que la interferencia en el goce y disfrute pacífico de las posesiones solo puede estar justificada en vistas a un interés público legítimo y reclama una evaluación de la proporcionalidad del objetivo propuesto. Criterios estos que no se cumplen si la interferencia supone una carga pesada y excesiva sobre la persona afectada ${ }^{139}$. Para el TEDH las garantías de procedimiento son exigencias de la certeza jurídica y del rule of law, ambos valores centrales del $\mathrm{CEDH}^{140}$.

El punto álgido de la argumentación, donde discrepa la minoría, se halla en la consideración de si la peticionaria tenía un interés legítimo de propiedad, pues según la ley de 2012 ella no cumplía con los requisitos legales para recibir la pensión de invalidez. Para estos disidentes, ampliar el concepto de intereses de propiedad supone considerar la seguridad social como derecho social plenamente exigible dentro del convenio en contra del mismo pacto. Para la mayoría, en cambio, el interés de propiedad deviene de la expectativa legítima que tenía la peticionaria a recibir un beneficio social, pues durante su período laboral contribuyó al sistema de forma obligatoria y luego, cuando enfermó, satisfizo los requerimientos de elegibilidad, por lo que podía razonablemente creer según la ley que le iban a reconocer los beneficios de invalidez ${ }^{141}$. Sin embargo, la modificación retroactiva de los requisitos para acceder al sistema sin medidas de transición para situaciones particulares como esta, que suponen una completa privación de las expectativas legítimas de la peticionaria, no permiten hacer un justo equilibrio entre los intereses en juego ${ }^{142}$. Nuestro análisis es que el TEDH más que un derecho autónomo de seguridad social está resolviendo la ausencia de un juicio independiente que revise la proporcionalidad de la medida. Por toda esta razón, percibimos que nuevamente se queda en un tercer $\left(3^{\mathrm{er}}\right)$ nivel de intensidad de los derechos sociales.

\section{CONCLUSIONES}

Este trabajo nos puso delante de una pregunta concreta: si es posible afirmar que el TEDH está adjudicando derechos sociales a pesar de la limitación de su pacto constitutivo, el CEDH, que es exclusivo de derechos civiles. Para responderla acometimos un análisis semántico sobre el concepto de derechos sociales y un ejercicio de interpretación de la jurisprudencia más reciente del TEDH al respecto. Conscientes de que la doctrina y la jurisprudencia se mueven en niveles distintos, a nivel abstracto los juristas conectan conceptos análogos y a nivel concreto los jueces aplican conceptos a hechos, intuimos que solo refinando el concepto de derechos sociales podríamos hacer una lectura aséptica de las sentencias del Tribunal de Estrasburgo ${ }^{143}$.

\footnotetext{
138 Confróntese con STEDH (GS) BÉLANÉ NAGY v HUNGARY, de 13 de diciembre de 2016 \$\$ 82, 88 y 113.

139 Confróntese con STEDH (GS) BEELANÉ NAGY v HUNGARY, de 13 de diciembre de $2016 \$ 115$.

140 Confróntese con STEDH (GS) BÉLANÉ NAGY v HUNGARY, de 13 de diciembre de $2016 \$ 89$.

141 Confróntese con STEDH (GS) BÉLANÉ NAGY v HUNGARY, de 13 de diciembre de $2016 \$ 105$.

142 Confróntese con STEDH (GS) BÉLANÉ NAGY v HUNGARY, de 13 de diciembre de $2016 \$ 124$.

143 Confróntese con Zambrano (2016) p. 61.
} 
$\mathrm{Al}$ analizar la jurisprudencia intentamos distanciarnos lo suficiente para escuchar los argumentos del Tribunal y evitar hacerle decir lo que realmente no dice. Para lograr esto, hicimos una revisión doctrinal que nos permitiese identificar el caso central y los casos de la penumbra de los derechos sociales y -en menor medida- de los derechos civiles. Así, encontramos cinco niveles de intensidad de los derechos sociales: (i) un primer nivel (caso central) de prestaciones materiales en sentido estricto per se; (ii) un segundo nivel de prestaciones materiales en consideración a un mínimo social; (iii) un tercer nivel de acciones de organización y procedimiento; (iv) un cuarto nivel de acciones positivas fácticas de protección; y, (v) un quinto nivel de acciones positivas normativas.

La revisión de la jurisprudencia enfocada tanto en el bien protegido por el Tribunal como en la conducta ordenada al Estado como reparación e iluminada por la propuesta del caso central y la penumbra de los derechos sociales resultó satisfactoria. Las sentencias analizadas nos permiten concluir que el TEDH no adjudica los derechos sociales en su caso central, sino que normalmente se queda en un tercer $\left(3^{\text {er }}\right)$ nivel de intensidad que identificamos con los derechos de organización y procedimiento. Esta conclusión nos permite matizar la opinión respecto a que los derechos sociales son exigibles judicialmente en el TEDH por medio de una conexión indirecta que permea un pacto de derechos civiles con contenido propio de los derechos sociales. A la luz de nuestra interpretación, y en base a los casos analizados, no se puede afirmar que los derechos sociales en su caso central sean justiciables en el Tribunal de Estrasburgo. Lo que sí se puede decir es que en esa sede se da una protección a los niveles de penumbra de los derechos sociales, consistentes en protecciones normativas, fácticas y adjetivas.

Esta última aclaración es importante, pues consideramos que leer la jurisprudencia del TEDH de forma extensiva a favor de una absoluta adjudicación de los derechos sociales podría llevar a optimismos infundados y a posteriores desengaños y expectativas frustradas. Salvaguardar la legitimidad de tribunales supranacionales como el TEDH reclama una claridad argumentativa que respete los márgenes de su pacto constitutivo ${ }^{144}$. Si el derecho se propone ordenar la conducta humana con palabras y no solo con fuerza, la creatividad judicial ciertamente inevitable, y la interpretación doctrinal deben respetar ciertos límites ${ }^{145}$.

Finalmente, queda pendiente para un ulterior estudio confirmar si al proteger los niveles de penumbra de los derechos sociales el TEDH está actuando fuera de su marco normativo, ya sea por adjudicar derechos intrínsecamente improcedentes o por interpretar extensivamente el CEDH sin respetar sus límites, o si, por el contrario, está simplemente reconociendo en la práctica que los derechos civiles del pacto y los derechos sociales ajenos a él tienen puntos comunes de contacto en sus respectivos niveles de penumbra, de forma que proteger los unos equivale necesariamente a proteger los otros.

144 Confróntese con Leijten (2013) p. 349; Leijten (2018) p. 32.

145 Confróntese con Zambrano (2016) p. 55 y 65. 


\section{BIBLIOGRAFÍA CITADA}

Abramovich, Víctor y Courtis, Christian (2009): "Apuntes sobre la exigibilidad judicial de los derechos sociales”, en Courtis, Christian y Ávila, Ramiro (eds.), La protección judicial de los derechos sociales (Quito, Ministerio de Justicia y Derechos Humanos) pp. 3-29.

Abramovich, Víctor y Courtis, Christian (2014): Los derechos sociales como derechos exigibles (Madrid, editorial Trotta).

Arcidiácono, Pilar y Gamallo, Gustavo (2017): "La justiciabilidad de los derechos humanos. Una lectura en clave de los problemas clásicos de la política social”, Nómadas. Revista Critica de Ciencias Sociales y Juridicas, vol. 50, № I. Disponible en: https://www. doi.org/10.5209/NOMA.53307. Fecha de consulta: 14 de mayo de 2018.

AlEXY, Robert (2007): Teoría de los derechos fundamentales (Theorie der Grundrechte), BERNAL, Carlos (trad.), (Madrid, editorial Centro de Estudios Políticos y Constitucionales, segunda edición en castellano).

Atria, Fernando (2004): “¿Existen derechos sociales?”, Discusiones: Derechos Sociales, N 4: pp. 15-59. Disponible en http://www.cervantesvirtual.com/nd/ark:/59851/bmcsf352. Fecha de consulta: 14 de mayo de 2018.

Bernal Pulido, Carlos (2004): "Fundamento, concepto y estructura de los derechos sociales. Una crítica a “¿Existen derechos sociales? de Fernando Atria, Discusiones: Derechos Sociales, $\mathrm{N}^{\circ}$ 4: pp. 99-144. Disponible en http://www.cervantesvirtual.com/nd/ ark:/59851/ bmcd50z4. Fecha de consulta: 14 de mayo de 2018.

BilchitZ, David (2014): "Socio-Economic Rights, Economic Crisis, and Legal Doctrine", International Journal of Constitutional Law, vol. 12, $\mathrm{N}^{\circ}$ 3: pp. 710-739.

BONET PÉrez, Jordi (2016): "La protección indirecta como instrumento de exigibilidad de los derechos económicos, sociales y culturales ante el Tribunal Europeo de Derechos Humanos", Derechos y libertades, N³5, época II, junio: pp. 137-183.

Bustos Bottai, Rodrigo (2012): "Derechos sociales y justiciabilidad: desmontando prejuicios", en Figueroa, Aída, Los Derechos Humanos en los umbrales del siglo XXI: una visión interdisciplinar (México, Instituto de Investigaciones Jurídicas UNAM) pp. 135-159.

BouazZa Ariño, Omar (2017): “Tribunal Europeo de Derechos Humanos: nuevos avances en la ponderación del concepto de sostenibilidad”, en López Ramón, Fernando (coord.) Observatorio de Políticas Ambientales 2017 (Madrid, editorial CIEMAT) pp. 83-104.

Brems, Eva (2007): "Indirect Protection of Social Rights by the European Court of Human Rights", en Exploring social rights. Between theory and practice (Portland, Hart Publishing) pp. 135-167.

Carbonell, Miguel (2009): "Eficacia de la Constitución y derechos sociales: esbozo de algunos problemas", en CourTis, Christian y Ávila, Ramiro (eds.), La protección judicial de los derechos sociales (Quito, Ministerio de Justicia y Derechos Humanos) pp. 55-87.

Carpintero, Francisco (2006): "Los Derechos Humanos de primera generación”, en MEGíAs, José Justo (edit.), Manual de Derechos Humanos (Navarra, Thomson Aranzadi) pp. 77-101. 
Cianciardo, Juan (2009): El principio de razonabilidad: del debido juicio sustantivo al moderno juicio de proporcionalidad (Buenos Aires, editorial Ábaco de Rodolfo de Palma, segunda edición).

CostA, Jean-Paul (2013): "Human Dignity in the Jurisprudence of the European Court of Human Rights", en McCrudden, Christopher (edit.), Understanding human dignity (Oxford, Oxford University Press) pp. 393-402.

Del Carril, Enrique (2012): "Notas para una fundamentación de los derechos sociales", Persona y Derecho, vol. 66, I: pp. 63-79.

Figueroa García-Huidobro, Rodolfo (2009-a): "Justificación del rol de las cortes haciendo justiciables los derechos económicos, sociales y culturales, en particular el derecho a la protección de la salud”, Revista Chilena de Derecho, vol. 36, № 2: pp. 313-342.

Figueroa García-Huidobro, Rodolfo (2009-b): "Justiciabilidad de los derechos económicos, sociales y culturales. Discusión teórica”, Revista Chilena de Derecho, vol. 36, № 3: pp. 587-620.

FinNis, John (2011): Natural Law and Natural Rights (Oxford, Oxford University Press, segunda edición).

Gearty, Conor (2013): "Socio-Economic Rights, Basic Needs and Human Dignity: A Perspective from Law's Front Line”, en McCrudden, Christopher (edit.), Understanding Human Dignity (Oxford, Oxford University Press) pp. 155-171.

Gerards, Janneke (2014): "The European Court of Human Rights and the national courts: giving shape to the notion of 'shared responsibility", en Gerards, Janneke y Fleuren, Joseph (edit.), Implementation of the European Convention on Human Rights and of the Judgements of the ECtHR in National Case-Law. A Comparative Analysis (Cambridge, Intersentia Publishing Ltd.) pp. 13-93.

Gerards, Janneke et al. (2018): Human Rights in the Council of Europe and the European Union, Achievements, Trends and Challenges (Cambridge, Cambridge University Press).

Jimena Quesada, Luis (2012): "La tutela de los derechos sociales: el espacio de la Unión y del Consejo de Europa”, en Cascajo, José Luis et al. (coord.) Derechos sociales y principios rectores. Actas del IX Congreso de la Asociación de Constitucionalistas de España (Valencia, editorial Tirant lo Blanch) pp. 135-163.

Jociene, Danute (2008): "Social Rights in the Jurisprudence of the European Court of Human Rights", Teise, vol. 66, No 2: pp. 21-43.

KInG, Jeff (2012): Judging Social Rights (Cambridge, Cambridge University Press).

Leijten, Ingrid (2013): "From Stec to Valkov: Possessions and Margins in the Social Security Case Law of the European Court of Human Rights", Human Rights Law Review, vol. 13, No 2: pp. 309-349.

LeIJTen, Ingrid (2018): Core Socio-Economic Rights and the European Court of Human Rights (Cambridge, Cambridge University Press).

López Guerra, Luis (2011): "La protección de derechos económicos y sociales en el convenio europeo de derechos humanos", Parlamento y Constitución, Anuario, N¹4: pp. 9-30.

Martínez Estay, José Ignacio (2010): "Los derechos sociales de prestación en la jurisprudencia chilena”, Estudios Constitucionales, año 8, N² 2: pp. 125-166. 
Mestre i Mestre, Ruth (2016): "La protección de los derechos sociales por el Tribunal Europeo de Derechos Humanos", Cuadernos Electrónicos de Filosofía del Derecho, №33: pp 113-132.

Mohor Abuauad, Salvador (2014) "El Recurso de Protección y los derechos sociales: Una deuda pendiente”, Revista de Derecho Público, Edición Especial: pp. 161-165.

Morales, Leticia (2015): Derechos sociales constitucionales y democracia (Madrid, editorial Marcial Pons).

Nivard, Carole (2016): "La justiciabilidad de los derechos sociales en el Consejo de Europa”, Lex Social: revista de los derechos sociales, vol. 6, № 2: pp. 12-33.

Peces BARBA, Gregorio (1998): "Los derechos económicos, sociales y culturales: su génesis y su concepto", Derechos y Libertades: Revista del Instituto Bartolomé de las Casas, N 6, año III: pp. 15-34.

PisARello Gerardo (2007): Los derechos sociales y sus garantías. Elementos para una reconstrucción (Madrid, editorial Trotta).

PRIETO SANChís, Luis (1995): "Los derechos sociales y el principio de igualdad sustancial”, Revista del Centro de Estudios Constitucionales, N²2: pp. 9-57.

Rieder, Clemens (2015): "Solidarity and Patient Migration in the Context of Fundamental Rights”, en Biondi, Andrea et al (eds.), Solidarity in EU Law: Legal Principle in the Making (Londres, editorial Edward Elgar) pp. 91-113.

Ruiz Albert, Miguel Ángel (2015): "Respuestas jurídicas de lege data al drama de los desahucios: la garantía del alojamiento alternativo y el desalojo social”, en ArelLANo Gómez, Francisco y Díaz Gómez, Manuel (coord.), Estudios jurídicos sobre vivienda y desahucios (Junta de Andalucía Consejería de Fomento y Vivienda) pp. 155-184. Disponible en: https://ws147.juntadeandalucia.es/obraspublicasyvivienda/publicaciones/01\%20ARQUITECTURA\%20Y\%20VIVIENDA/estudios_juridicos_sobre_ vivienda_y_desahucios/texto_completo.pdf. Fecha de consulta: 14 de mayo de 2018.

Schabas, William (2015): The European Convention on Human Rights a Commentary (Oxford, Oxford University Press).

Silva Portero, Carolina (2009): "Los derechos sociales y el desafío de la acción de protección”, en Courtis, Christian y Ávila, Ramiro (eds.), La protección judicial de los derechos sociales (Quito, Ministerio de Justicia y Derechos Humanos) pp. 577-616.

Solari, Enzo y Vera, Christian (2015): "Justiciabilidad de los derechos sociales (a propósito de una argumentación de Fernando Atria)", Estudios Constitucionales, año 13, № 2 : pp. 13-56.

Soto Velasco, Sebastián (2008): "Fallo Isapres: una mirada a los derechos sociales y el rol de los jueces”, Sentencias destacadas: pp. 171-213.

UlloA, Ana y Chávez, Ana (2015): "Sobre las relaciones ontológicas entre los derechos individuales y los DESC. Un universalismo a posteriori”, en ZÚNIGA, Alejandra y CóRдовA, Enrique (Dir.), Derechos sociales. Políticas públicas, exigibilidad, justiciabilidad (Pamplona, editorial Thomson Reuters Aranzadi) pp. 289-298.

Volou, Aristi (2017): "The Protection of Socio-Economic Rights through the Canon of Civil and Political Rights: A Comparative Perspective", Groningen Journal of International Law, vol. 5, $\mathrm{N}^{\circ} 2$ : pp.147-167. 
Zambrano, Pilar (2009): La inevitable creatividad en la interpretación juridica. Una aproximación iusfilosófica a la tesis de la discrecionalidad (México, editorial Instituto de Investigaciones Jurídicas).

Zambrano, Pilar (2013): "Principios fundamentales como determinación de los principios morales de justicia”, en Etcheverry, Juan Bautista (edit.) Ley, moral y razón. Estudios sobre el pensamiento de John M. Finnis a propósito de la segunda edición de Ley natural y derechos naturales (México, editorial Instituto de Investigaciones Jurídicas) pp. 87-118.

Zambrano, Pilar (2016): "Interpretar es conocer. Una defensa de la teoría referencialista de la interpretación”, en Cianciardo, Juan et al. (coord.) Filosofía práctica y Derecho. Estudios sobre teoría juridica contemporánea a partir de las ideas de Carlos Ignacio Massini Correas (México, editorial Instituto de Investigaciones Jurídicas) pp. 53-73.

\section{JURISPRUDENCIA CITADA}

STEDH AIREY v. IRELAND, No 6289/73, de 9 de octubre de 1979.

STEDH (Gran Sala) STEC and OTHERS v. UNITED KINGDOM, No 65731/01 y 65900/0, de 12 de abril de 2006.

STEDH MCCANN v. THE UNITED KINGDOM, No 19004/04, de 13 de mayo de 2008.

STEDH TRZEPALKo v. Poland, No 25124/09, de 13 de septiembre de 2011.

STEDH Wiater v. POLAND, No 42290/08, de 15 de mayo de 2012.

STEDH ŠKRTIC v. CROATIA, No 64982/12, de 5 de diciembre de 2013.

STEDH IVANOVA and CHERKEZOV v. Bulgaria, No 46577/15, de 21 de abril de 2016.

STEDH IRINA SMIRNOVA v. UKRAINE, No 1870/05, de 13 de octubre de 2016.

STEDH (Gran Sala) BÉLANÉ NAGY v. HUNGARY, No 53080/13, de 13 de diciembre de 2016. 